\title{
Correction to: Chapter 1: Introduction to Energy in Africa: Policy, Management, and Sustainability
}

\section{Sola Adesola and Feargal Brennan}

\section{Correction to:}

Energy in Africa

https://doi.org/10.1007/978-3-319-91301-8

This chapter was inadvertently published with errors. Footnotes, citations and references were added.

The updated online version of this chapter can be found at https://doi.org/10.1007/978-3-319-91301-8_1

\author{
S. Adesola $(\square)$ \\ Oxford Brookes Business School, Oxford Brookes University, Oxford, UK \\ e-mail: sadesola@brookes.ac.uk \\ F. Brennan \\ University of Strathclyde, Glasgow, UK \\ e-mail: feargal.brennan@strath.ac.uk
}

